Influencia cultural del anime japonés en la recepción de estudiantes de Diseño gráfico de la Universidad de Guayaquil

Dialmar José Intriago Córdova, Tomás Rodríguez Caguana

http://perio.unlp.edu.ar/ojs/index.php/question/article/view/4694

Cita sugerida: Intriago Córdova, D., y Rodríguez Caguana, T. (2018). Influencia cultural del anime japonés en la recepción de estudiantes de Diseño gráfico de la Universidad de Guayaquil. Question, 1(59), e084.

\title{
Influencia cultural del anime japonés en la recepción de estudiantes de Diseño gráfico de la Universidad de Guayaquil
}

\author{
Cultural influence of Japanese anime in the reception of Graphic \\ Design students of the University of Guayaquil
}

Dialmar José Intriago Córdova dialmar.intriagoc@ug.edu.ec

http://orcid.org/0000-0002-4335-7240

Universidad de Guayaquil (Ecuador)

Tomás Rodríguez Caguana tomas.rodriguezc@ug.edu.ec

http://orcid.org/0000-0002-4673-9295

Universidad de Guayaquil (Ecuador)

\section{Resumen}

Este artículo analiza la influencia cultural del anime japonés en la recepción comunicológica de los estudiantes de primer a tercer semestre de la carrera de Diseño gráfico en la Universidad de Guayaquil en 2017, teniendo como objetivo determinar la influencia cultural del anime japonés en la recepción comunicológica de dichos estudiantes. La hipótesis que se aborda es que la influencia cultural del anime japonés se origina por la recepción comunicológica de contenidos japoneses a través de la construcción de imaginarios sociales en los estudiantes de la carrera de Diseño gráfico. Las variables que se indagan son recepción comunicológica e 
imaginarios sociales, direccionado a un tipo descriptivo a través de un diseño no experimentaltranseccional. La metodología que se utiliza es el interaccionismo simbólico por medio de ocho técnicas. Los resultados del estudio exponen un proceso de interculturalidad que se ha construido por representaciones socioculturales imaginarias a partir de la recepción a diversos elementos culturales dentro del anime japonés.

Palabras clave: comunicación; recepción comunicológica; imaginario social; anime; interculturalidad.

\section{Abstract}

The problem of this research how does the Japanese anime culturally influence on the communicational reception of the first semester students of the Graphic Design career at the University of Guayaquil in 2017? The objective is to determine the cultural influence of the Japanese anime in the communication reception of said students. The hypothesis: the cultural influence of Japanese anime originates from the communicational reception Of Japanese content through the construction of social imaginaries in the students of the Graphic Design career. The variables are communication reception, social imaginary. The type of this descriptive research is the design is non experimental-transectional. The methodology: symbolic interactionism. In this research it was used 8 techniques divided into four qualitative and quantitative. Results: hypothesis tested. Proposal is to create conference "the interculturality of the Japanese anime in Guayaquil audiences" and to study the imaginary socio-cultural construction of the anime on the audiences of these cultural phenomena.

Keywords: communication; communication; social imagination; anime; interculturality.

El trabajo de investigación, "análisis de la influencia cultura del anime japonés en la recepción comunicológica de los estudiantes de primer a tercer semestre de la cerrera de Diseño Gráfico en la Universidad de Guayaquil, permite entender la construcción de una interacción cultural que muestra el anime a través de la interacción comunicativa con estos productos que tienen las audiencias.

Dentro del análisis de la interculturalidad en que las audiencias se ven atraídas está la ola japonesa la cual los fanáticos se encuentran pendientes de nuevos contenidos de sus series 
animes favoritos, esto gracias al desarrollo de una cultural nipona posicionada por la globalización siendo la animación un porta estandarte de exportación.

El problema de investigación que asume este trabajo es; ¿cómo influye culturalmente el anime japonés en la recepción comunicológica de los estudiantes de primer a tercer semestre de la facultad de Diseño gráfico en la Universidad de Guayaquil del año 2017?

Dentro de este estudio se destaca el análisis y métodos en que el anime va construyendo nuevas formas de socialización dentro de un contexto determinado. Así mismo determinar una explicación del fenómeno y sus efectos con nuevos enfoques investigativos pocos abordados para conocer el grado de recepción e influencia cultural de estas series en la actualidad.

El objetivo principal de la investigación es determinar la influencia cultural del anime japonés en la recepción comunicológica en los estudiantes de primer semestre a tercer semestre de la carrera de Diseño gráfico de la Universidad de Guayaquil en 2017.

\section{Revisión de literatura}

\section{Comunicación y recepción}

La comunicación es el proceso de interacción social donde el ser humano construye intercambios de pensamientos y emociones que permite crear vínculos sociales y culturales con el objetivo de una estructura social organizada.

Habermas expone que la comunicación en los procesos culturales es una actividad convergente expuesta desde una forma lingüística:

la comunicación lingüística y la tradición cultural que a ella afluye sólo emergen como una realidad con derecho propio frente a la realidad de la naturaleza y de la sociedad a medida que se diferencian conceptos formales de mundo y pretensiones de validez no empíricas (2011: 81).

La comunicación tiene su propio sentido no solo como una forma de expresión cultural, sino como el significado lingüístico de pertenencia tradicional de una sociedad que ha desarrollado de forma natural. Asimismo exponen que esta realidad comunicacional tiende a ser significativa y que debe ser analizada de forma integral no solo con conceptos de una realidad dentro de una situación objetiva. 
Los procesos sociales generan las formas de comunicación; es decir que las interacciones socioculturales forjan no solo las estructuras sino el proceso comunicacional que se utiliza en cada uno de ellas, siendo la lingüística la vía principal en la cual se desarrollan las acciones y comportamientos de los grupos e individuos.

Para Manuel Martin Serrano la comunicación,

es actividad social indisociable de la construcción del presente y de la transformación del futuro. Y porque los estudios de la comunicación tienen fundamento científico. Según me parecía, y parece que, las ciencias de la comunicación pueden alcanzar la dimensión antropológica (2014: 4).

El acto comunicativo es un instrumento que no se puede separar de la sociedad, pues es por medio de la comunicación es que el desarrollo de los conglomerados sociales toma forma. Los objetivos presentes y futuros de los grupos se analizan, se debaten y se forman mediante el sistema de comunicación que tengan.

\section{Influencia cultural}

La influencia cultural es el proceso de desarrollo individual y social que los seres humanos experimentan por medio de la interactividad con el medio que le rodea. Los procesos comunicativos juegan un papel fundamental en esta experimentación, pues permite la integración adecuada al entorno.

Edgar Morín, desde de un punto de vista antropológico, expone:

El feto sufre influencias culturales en su vida intrauterina (alimentos, sonidos, músicas) y desde su nacimiento el individuo comienza a recibir el legado cultural que asegura su formación, su orientación, su desarrollo como ser social; sufre tabúes, imperativos, normas (que se inscriben cerebralmente por estabilización selectiva de sinapsis), y en él se fijan los automatismos sociales (2000: 4).

A partir del punto de vista antropológico se destaca que el ser humano recibe influencias culturales desde su concepción biológica y resalta el proceso individual que tienen las personas 
a partir de los seleccionados influjos culturales que reciben y experimenta socialmente, entre ellos la comunicación.

Dentro de los estudios de comunicación y cultura, Andrea Bordei afirma que:

la cultura influencia la comunicación. Todos los grupos culturales influencian la manera en la cual los miembros experimentan y perciben el mundo. Los miembros de una cultura crean una visión sobre el mundo, cual, sucesivamente, influencia la comunicación. (...) La cultura se está comunicando a sí misma, especialmente a los otros (personas y entidades que no pertenecen a esa cierta cultura). Por eso, ciertos comportamientos y ciertas creencias, actitudes llegan a ser marca de una cultura en la visión general externa sobre esa cultura (2010: 23).

La integración entre la cultura y el proceso de comunicación es explicada cuando un grupo social está formado culturalmente y maneja diferentes formas de comunicación para integrar a nuevos conglomerados sociales e influirlos en su percepción del mundo. Esta convergencia no solo debe ser estudiada desde un punto de denuncia, abstrayendo identificaciones de un solo fenómeno, como las industrias culturales, sino generar que las nuevas indagaciones científicas viabilicen posturas críticas sobre las estructuras sociales en contextos globalizados que permitan nuevas disyuntivas en los procesos de recepción comunicacional.

\section{Recepción comunicológica}

La recepción comunicológica como base de este estudio permite entender como los contenidos interactúan con los perceptores y generan nuevas expresiones culturales.

En los estudios de recepción de Jesús Martín-Barbero expresa que:

Fue así como la comunicación se nos tornó cuestión de mediaciones más que de medios, cuestión de cultura y, por tanto, no sólo de conocimientos sino de re-conocimiento. Un reconocimiento que fue, de entrada, operación de desplazamiento metodológico para re-ver el proceso entero de la comunicación desde su otro lado, el de la recepción, el de las resistencias que ahí tienen su lugar, el de la apropiación desde los usos (2010: 16).

El cambio de corriente que propone la recepción y sus estudios dejan de lado las posturas influyentes mecanicistas donde el papel principal lo jugaban los medios de comunicación 
siendo el centro de la espiral comunicativa. El autor reconoce que el protagonista es la cultura como el principal factor dentro del contexto de desarrollo siendo la recepción el anclaje para entender los contenidos comunicacionales que recibimos en la actualidad.

Analizar el sistema en que funciona la comunicación; los estudios de recepción nos permiten entender los diferentes contextos en que participan las audiencias con los contenidos no solo desde una óptica influyente, pues la interactividad sociocultural el cual los participantes muestran sus intereses y se identifican. Estas determinaciones plantean el estudio de la interacción del anime japonés

En el trabajo de Leticia Porto, Proceso de socialización y cine de animación de Disney, se observa:

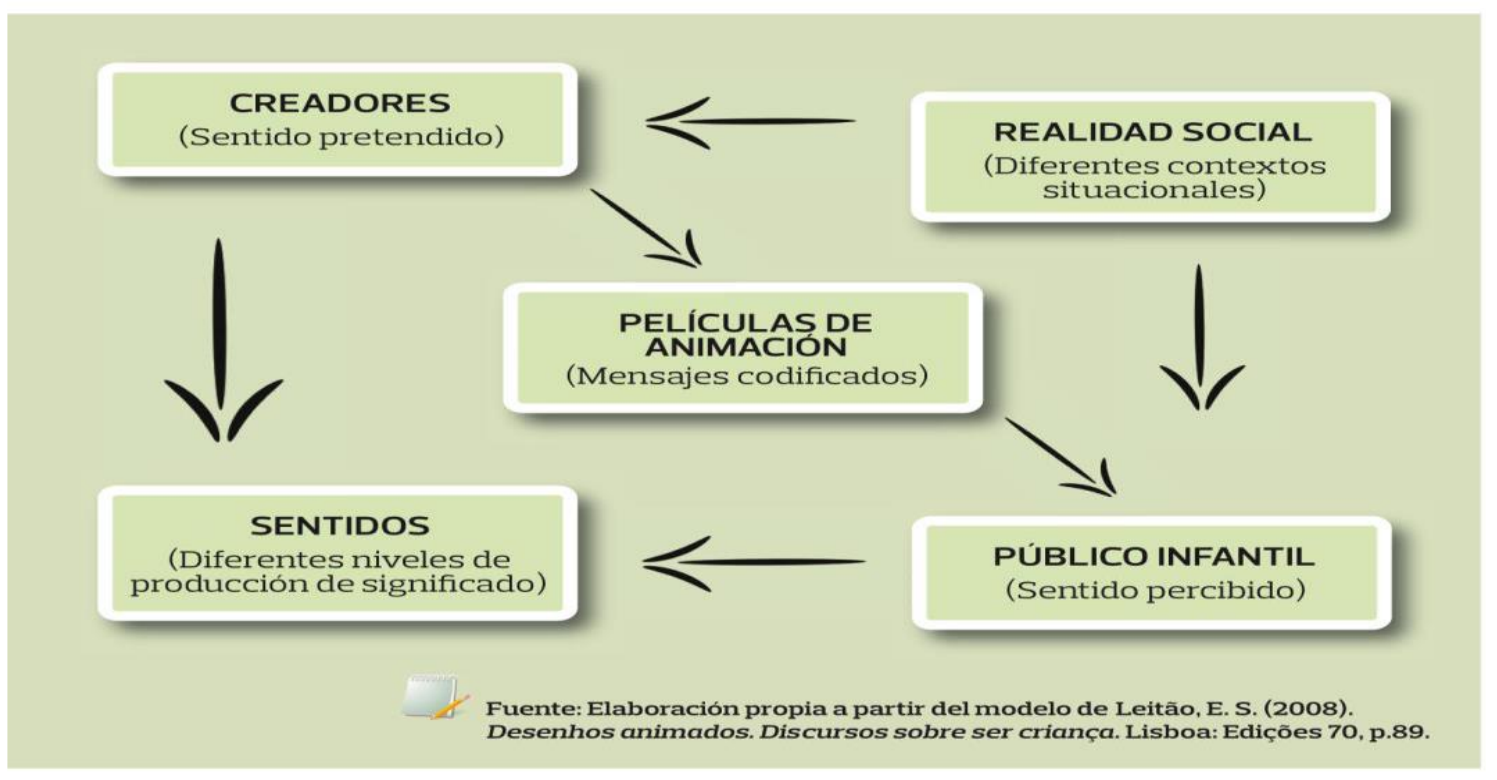

Figura 1: Factores en la producción y recepción de mensajes mediáticos (Porto, 2014).

En la imagen se ilustra la interacción e interrelación que tiene el proceso de recepción junto a los elementos que trabajan en el mismo. Entre los factores que participan esta la parte creativa de los mensajes, que es donde se codifican los sentidos por medio de contenidos dentro de materiales audiovisuales que la audiencia va a recibir. Para codificar estos contenidos, son analizados los varios contextos socioculturales y sus características, determinando que tipos mensajes comunicacionales podrán ser transmitidos esperando una alta aceptación. 
Dialmar José Intriago Córdova, Tomás Rodríguez Caguana. Influencia cultural del anime japonés en la recepción de estudiantes de Diseño gráfico de la Universidad de Guayaquil

\section{Anime}

El anime japonés es un fenómeno visual introducido por las industrias culturales que tiene la capacidad de generar sentidos, intereses y gustos entre los perceptores. El estudio sobre anime del autor Juan Martínez, La filosofía del viento: un análisis del lenguaje en el cine de Hayao Miyazaki se observa:

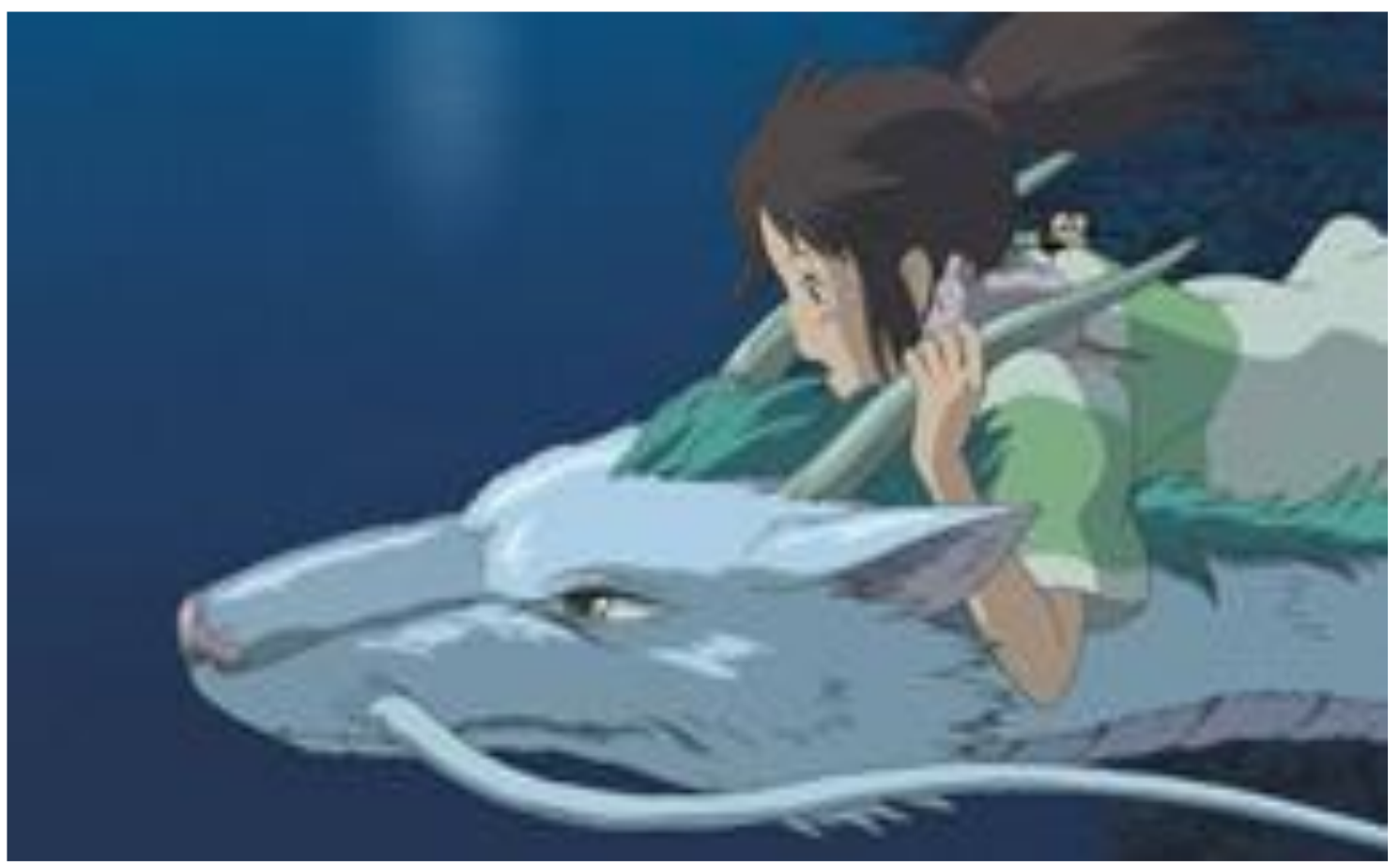

Figura 2: El viaje de Chihiro. Martínez (2015).

En la imagen se puede visualizar el anime El viaje de Chihiro, del director Hayao Miyazaki, esta animación forma parte de las obras más grandes del cine japonés realizada por los estudios cinematográficos Ghibli. Los recursos culturales que utiliza el director en la animación de la película están ligados abiertamente a promover la cultura japonesa donde muestra un anime lleno de templos, historia, mitología y gastronomía. El proceso de interacción entre los elementos culturales dentro de la trama que desarrolla este anime, permite entender la conexión tradicional, histórica y religiosa de la propuesta cinematográfica en torno a una proyección cultural permanente.

Asimismo el anime japonés como estudio es indagado por Luis Carazo quien afirma: 
aprendemos más de un anime japonés, porque en ella se cuentan futuros posibles, los personajes son complejos, las historias son cercanas a nuestros intereses, mientras que los libros de texto que hablan de Japón parecen mostrar una cultura que no tiene nada que ver con nosotros (2015: 163).

El interés del anime en la actualidad se da por las estructuras en las historias que muestran, pues estas permiten abrir una ventana hacia Japón junto a su cultura. Además, la animación nipona no solo se alimenta de la cultura de su país, sino que absorbe una cultura globalizada. Seguido a esto, el éxito mundial del anime japonés se analiza por los recursos que utilizan los autores dentro de lo novedoso de las historias el cual no faltan elementos culturales de su país como eje dentro de las narrativas.

Dentro del campo de recepción del anime como un producto cultural, Yanina Torti sostiene:

\begin{abstract}
las redes sociales, foros y galerías se maximiza por su fácil ingreso y el mantenimiento monetario nulo por parte del usuario. Estos sitios se han convertido en espacios de encuentro para generar salas de debate, discusiones y mensajes de respuesta sobre temas en común. Muchos aportes y productos culturales se comparten desde aquí, del mismo modo en que se interconectan personas mediante la predisposición a una interacción directa virtual, ya sea mediante artículos, fotos, imágenes, animaciones y conversaciones por chat o mensajes" (2016: 23).
\end{abstract}

Las redes sociales son un punto de encuentro donde los receptores de series de animación japonesa dinamizan diferentes contenidos y los usuarios puedan socializar. Los grupos sociales que se construyen interactúan entre sí, forjando interesen en común lo que permite nuevas predisposiciones imaginarias para seguir participando y buscando formas de expresiones culturales que llenen las expectativas de lo que consumen.

\title{
Cultura japonesa
}

El desarrollo cultural del país nipón es parte de un proceso histórico que ha fortalecido su identidad como sociedad. Así mismo le ha permitido forjar elementos culturales posicionados 
Dialmar José Intriago Córdova, Tomás Rodríguez Caguana. Influencia cultural del anime japonés en la recepción de estudiantes de Diseño gráfico de la Universidad de Guayaquil

en el mundo. El anime, manga, la gastronomía y la tecnología entre otros, son plataformas que reinventa la perspectiva de Japón.

En los estudios de Irina Martínez en el que estudia a Japón dice:

la cultura japonesa, en especial, tiene en su haber un amplísimo abanico de símbolos cuyos significados puede llegar a ser múltiples y muy complejos. Roland Barthes, en su obra El Imperio de los Signos, trata de profundizar en la simbología que envuelve a Japón con tal de intentar establecer un sistema en base a sus rasgos gráficos y lingüísticos (2014: 16).

La ola cultural japonesa que genera una diversidad de productos culturales. Estos sirven de representaciones mentales que permiten descifrar el sistema sociocultural japonés. Así mismo penetrar a la cultura nipona es chocar con los sentidos semióticos que tiene Japón en su industria cultural, esta exporta a occidente constituyendo una supremacía que sirve de estudio para comprender nuevas formas, códigos y estereotipos socioculturales que toman fuerza actualmente.

Dentro del anime autores como Rolando Rodríguez analizan los simbolismos de las estructuras del anime e ilustra:

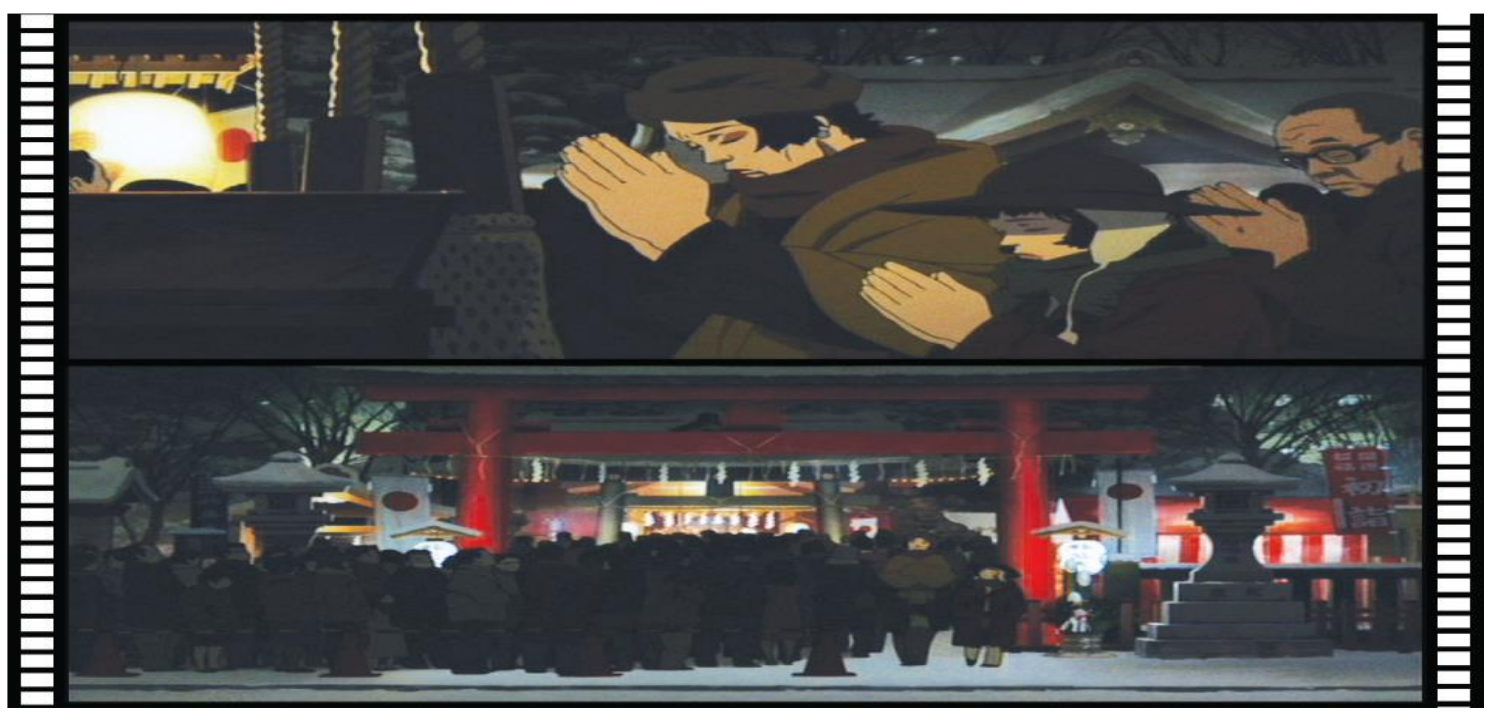

Figura 3: Hana y Miyuki rezan en un sintoísta, en la imagen inferior el torii rojo. Rodríguez (2014).

En la imagen se observa la construcción de contenidos en dos planos de un a animación y como se aprovecha esta plataforma para mostrar un aspecto cultural que tienen esta sociedad 
oriental. En este caso muestra la religiosidad, que esta graficada por la presencia iconográfica del Tori que se encuentra a la entrada de los templos sintoísta, además en este fotograma extraído de un anime se visualiza los diferentes elementos culturales que se conjugan sobre las prácticas religiosa, exteriorizadas por la forma que interactúan los personajes.

\section{Imaginarios sociales}

La formación de imaginarios sociales interiorizados y representados por diversas audiencias es parte de la construcción de narrativas culturales que permiten entender diversos aspectos de pertenencia que engloban matices culturales y conjuga una interacción social.

Expresiones culturales como el cosplay se visualiza en estudios de Pedro Morales y muestra:
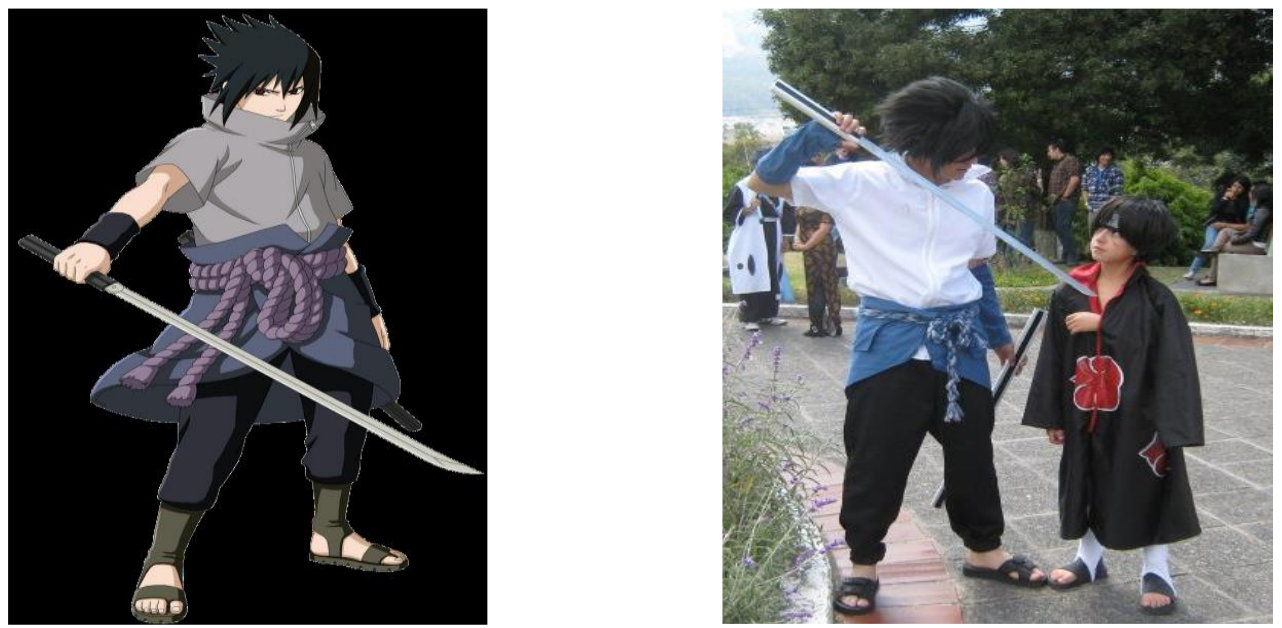

Figura 4: Sasuke Uchiha de la serie Naruto Shippuden. Morales (2015).

En la imagen se observa al anime japonés como herramienta que genera la participación de la actividad cosplay, siendo este, un efecto de la construcción de imaginarios socioculturales que permite identificar al individuo en una relación con la temática audiovisual que recibe e identifica. De igual forma las representaciones sociales que tiene el receptor cuando enfrenta contenidos compuestos en los animes, no solo sirve para forjar sentidos, sino que busca implantar acciones concretas forjando una identificación ligada a otras formas culturales que guarda la industria cultural japonesa.

Así mismo sobre estos productos culturales y sus imaginarios Henry Jenkins sostiene que: 
Se aprecia una poderosa influencia de los mangas y los animes (cómics japoneses), con la silia de cuero rojo como homenaje a Akira (1988) y el mono de Trinity directamente inspirado en Ghost in the Shell (1995). Posiblemente, todo su interés por la narración transmediática pueda remontarse a esta fascinación con lo que la antropóloga Mimi lto ha descrito como la cultura de la «mezcla mediática» de Japón (2006: 115).

Los productos culturales sirven como plataforma para forjar imaginarios sociales, siendo estos elementos como los animes y mangas, contenidos imponentes dentro de la ola japonesa que expresa las características socioculturales en la sociedad que tiene un país. La relación directa que tienen los interesados en la animación japonesa permite para la difusión de su variedad de propuestas culturales (cosplay, videojuegos, idioma, tradiciones) y que contribuyen al constante crecimiento de nuevos imaginarios que diversifica su aceptación en diferentes contextos.

\section{Nuevas bases teóricas de la Recepción comunicológica y los contenidos e imaginarios sociales}

La recepción comunicológica dentro del marco de los imaginarios sociales se da por la interactividad que tienen los receptores con los contenidos de estas series.

En trabajos sobre recepción el autor Arturo Dávila sostiene que:

un mensaje no incide en el receptor debido a la naturaleza del mismo, sino debido al bagaje cultural del que lo percibe; es decir, el receptor se convierte en un filtro a través del cual pasan los mensajes, siendo interpretados de manera diferente a como lo haría el sujeto sino hiciera una reapropiación de los significados (2016: 25).

En el acto comunicativo el receptor escoge un contenido le da una identificación al mismo, asociada a sus características socioculturales. La interpretación y la formación de sentidos están ligadas al grado de impacto del mensaje. El amplio campo de recepción por parte de la audiencia permite que los significados interactúen con el receptor que impondrá nuevos códigos comunicológicos.

Por otra parte, el estudio de imaginarios sociales de la autora María González afirma: 
a partir de los imaginarios sociales se producen, los valores, las apreciaciones, los gustos, los ideales y la conducta de estas personas que conforman una cultura (...). Es a partir de este proceso cómo las personas, a través de la imaginaria, colectiva disponen parámetros y referencias para actuar. Pero los juicios y las actuaciones de las personas inciden también en el dispositivo imaginario, el cual, como contrapartida funciona como idea reguladora de conducta (González, 2016: 18).

La formación de imaginarios sociales es una producción colectiva de sentidos que pertenecen culturalmente a un grupo específico de personas que se identifican con ellos, este fenómeno se independiza de las individuales del sujeto dándole una identidad propia. Los ideales son esos imaginarios que expresan valores y comportamientos que integran una sociedad.

\section{Metodología}

Esta investigación asume un diseño no experimental-transeccional donde las variables recepción comunicológica e imaginario social no se modifican, analizando el fenómeno los últimos cuatro meses en la carrera de Diseño gráfico. El tipo es descriptivo porque se busca la descripción de las variables. Además, sigue la corriente filosófica del interaccionismo simbólico, donde el sujeto concibe el conocimiento a partir de la interacción de las configuraciones interpretativas-simbólicas generando significados compartidos en los conglomerados sociales, como respuesta dentro de un contexto determinado.

\section{Hipótesis}

La influencia cultural del anime japonés se origina por la recepción comunicológica de contenidos japoneses a través de la construcción de imaginarios sociales en los estudiantes de la carrera de Diseño gráfico. 


\begin{tabular}{|c|c|c|}
\hline Variables & Dimensiones & Indicadores \\
\hline \multirow{4}{*}{$\begin{array}{c}\text { Recepción } \\
\text { comunicológica }\end{array}$} & \multirow[b]{2}{*}{$\begin{array}{l}\text { Interacción de contenidos } \\
\text { japoneses }\end{array}$} & $\begin{array}{l}\text { Formas de consumo de los } \\
\text { contenidos japoneses }\end{array}$ \\
\hline & & $\begin{array}{l}\text { Tiempo de consumo de contenidos } \\
\text { japoneses }\end{array}$ \\
\hline & \multirow[b]{2}{*}{ Recepción de contenidos } & Impacto cultural \\
\hline & & Elementos culturales \\
\hline \multirow{4}{*}{ Imaginario social } & \multirow[t]{2}{*}{ Construcción de aficiones } & $\begin{array}{l}\text { Cuerpo como forma de expresión de } \\
\text { ficciones }\end{array}$ \\
\hline & & Identificación visual \\
\hline & \multirow[t]{2}{*}{ Interculturalidad/Transculturización } & Nuevas representaciones sociales \\
\hline & & Respuesta sociocultural \\
\hline
\end{tabular}

Tabla 1: Operacionalización de las variables. Dialmar Intriago (2017).

\section{Población y muestra}

Esta investigación se desarrolla bajo una población de 160 estudiantes, siendo la selección de una muestra no probabilística -por cuotas con 100 personas, donde se emplea una división de la población por grupos dentro de diferentes características.

Los diferentes criterios elegidos dentro de este muestreo por cuotas son:

-Estudiantes que visualicen anime cada día en su idioma original.

-Que identifiquen nombres de anime con fuerte carga cultural y las costumbres japonesas que participan.

-Que caractericen más de tres veces al mes a su personaje favorito.

-Que participen en eventos independientes o realizados por la embajada japonesa donde se promueva la cultura nipona.

-Que interactúen cada día en páginas y grupos de Facebook en conjunto a canales de youtube donde se promuevan contenidos culturales sobre Japón. 


\section{Técnicas de Investigación aplicada}

Las técnicas que se utilizaron en esta investigación fueron ocho, divididas en cualitativas y cuantitativas.

Técnicas Cualitativas

-Investigación bibliográfica.

-Test proyectivo.

-Situación ideal.

-Cambio de rol.

-Inserción de texto.

Técnicas Cuantitativas

-Encuesta.

-Escala de Likert.

-Escala de intensidad.

-Escala de puntos.

Estas técnicas de investigación tantos cualitativas como cuantitativa son las bases que permiten obtener la información del público muestral. Dentro del proceso de abstracción de información de plantearon preguntas las cuales englobaron estas técnicas a los estudiantes de Diseño gráfico de la Universidad de Guayaquil.

\section{Hallazgo}

Variable: Recepción comunicológica.

Dimensión: Interacción de contenidos japoneses.

Indicador: Forma de consumo de contenidos japonenses.

Técnica cuantitativa: Encuesta.

1. ¿Consume contenido japonés y anime a través de internet y redes sociales? 


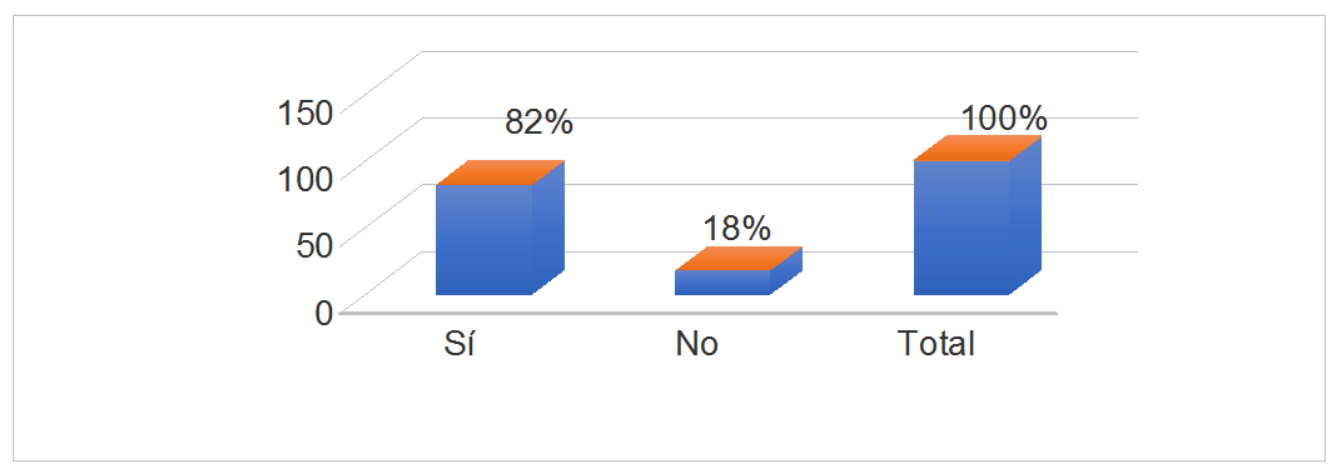

Gráfico 1: recepción del anime. Dialmar Intriago (2017).

Los resultados en esta pregunta muestran que existe un alto consumo de la animación japonesa por medio de las redes sociales y el internet en general. La aceptación del sí, con un $82 \%$, frente al no, con un $18 \%$, esto establece que la audiencia interactúa eficazmente por los medios digitales, asumiendo fuentes de información actualizada sobre las series y contenidos provenientes de Japón que son de su interés.

Variable: Recepción comunicológica.

Dimensión: Recepción de contenidos.

Indicador: Elementos culturales.

Técnica: Escala de puntos.

2. Los elementos culturales que se presentan dentro de las estructuras narrativas del anime y los contenidos japoneses son...

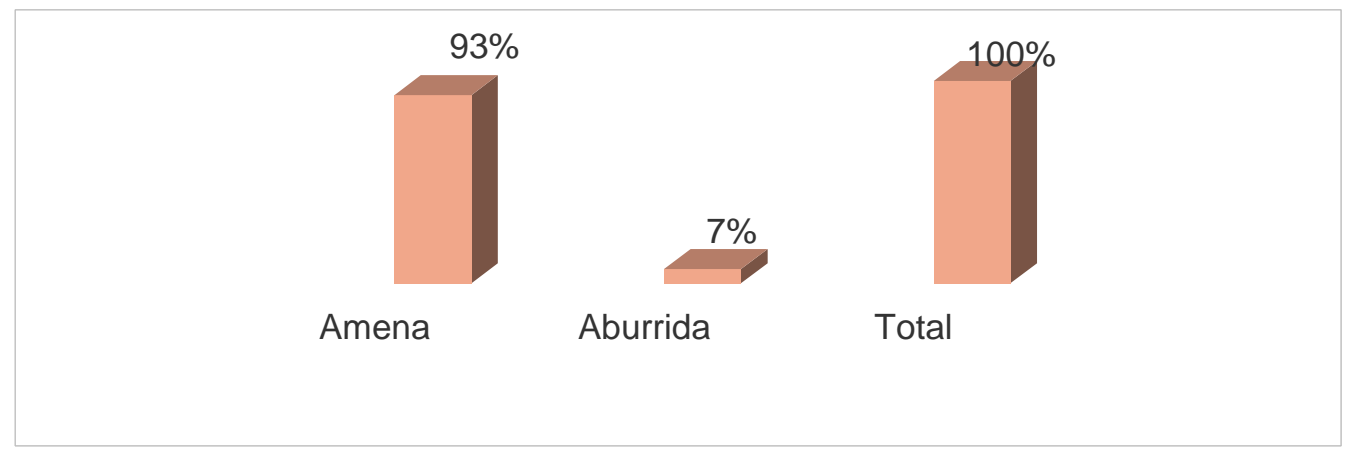

Gráfico 2: aceptación de elementos culturales. Dialmar Intriago (2017). 
Los abordados afirmaron con un $93 \%$ que les parece ameno que en las estructuras narrativas que muestra el anime existan elementos culturales que les permitan tener una interculturalidad ola japonesa. Por otro lado, un 7\% manifestaron que les parecen aburridos dichos elementos. Esto establece que el anime forja no solo un acercamiento con la cultura nipona, sino que permiten entender comportamientos y costumbres que se posicionan en las audiencias que disfrutan amenamente de estos contenidos.

Variable: Recepción comunicológica.

Dimensión: Interacción de contenidos japoneses.

Indicador: Tiempo de consumo de contenidos japoneses.

Técnica: Encuesta

3. ¿Es importante para usted el tiempo que dedica a visualizar y consumir anime y contenido japonés?

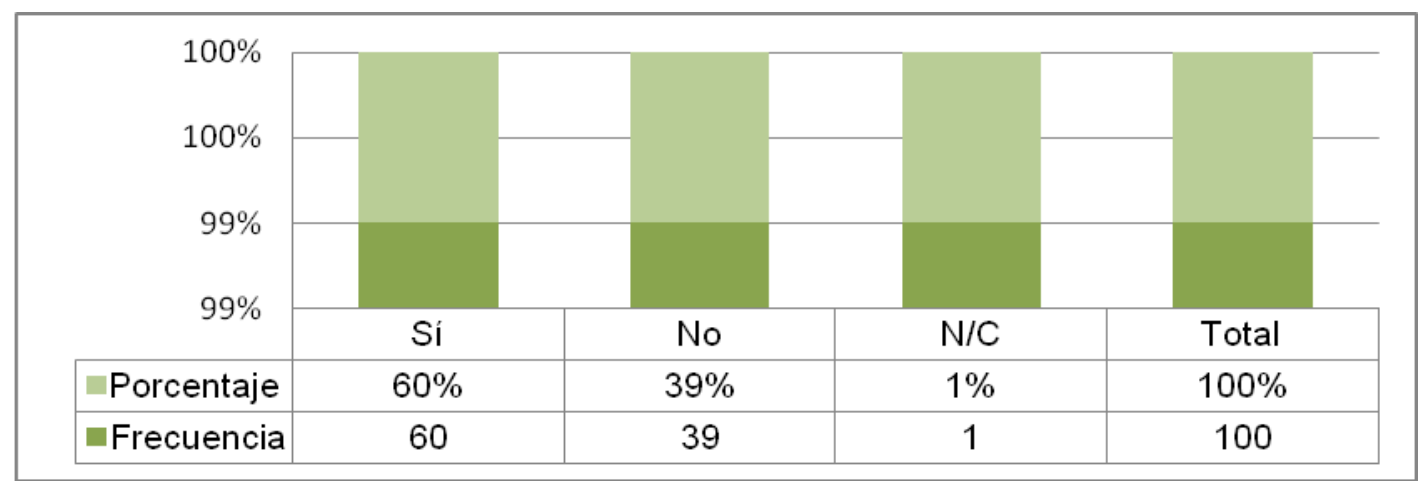

Gráfico 3: interacción con el anime. Dialmar Intriago (2017).

Análisis: los abordados sostuvieron con un $60 \%$ que el tiempo que visualizan la animación y contenido de origen japonés es importante para ellos admitiendo una interactividad, mientras que un $39 \%$ afirmó que no genera un sentido de importancia, aunque si lo visualizan. A partir de estas cifras se analizan que las audiencias forjan una interacción y exposición gradual ciertos contenidos a partir del tiempo de consumo.

Variable: Recepción comunicológica.

Dimensión: Recepción de contenidos.

Indicador: Elementos culturales.

Técnica: Cambio de rol. 
4. Si usted fuera el embajador de Japón en Ecuador ¿qué métodos de difusión utilizaría para generar una recepción más activa de los elementos culturales en las audiencias?

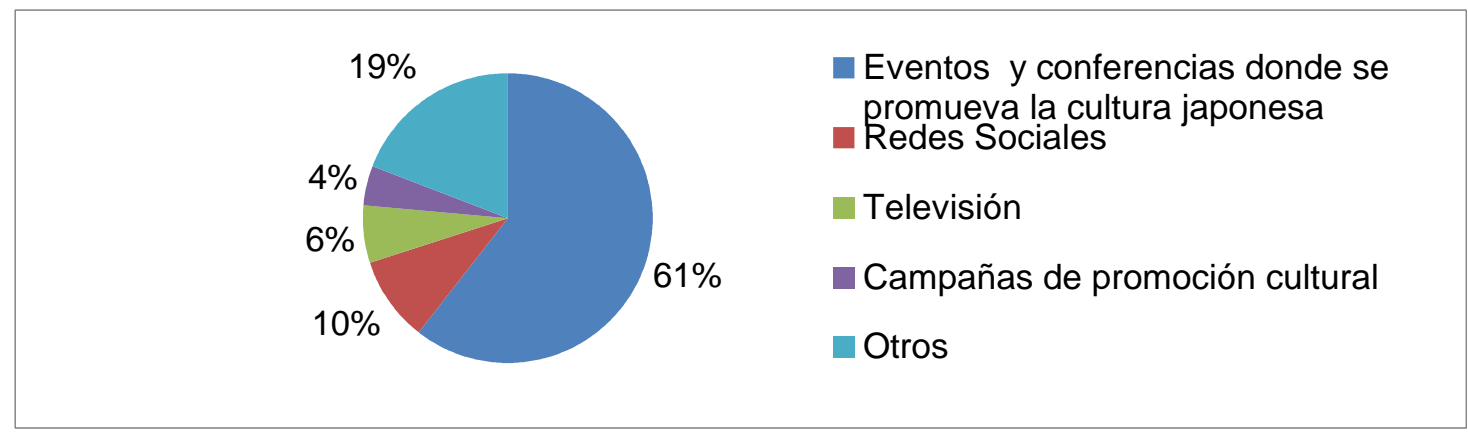

Gráfico 4: aceptación de elementos culturales. Dialmar Intriago (2017).

Los abordados manifestaron que en el rol del embajador de Japón en el Ecuador generaría una recepción más activa de estos elementos a través de eventos y conferencias sobre la cultura nipona con un $61 \%$, mientras que otro grupo manifestó con un $10 \%$ que la difusión por redes sociales ayudarían al impulso cultural generando noticias especializada sobre el país introduciendo sus costumbres y tradiciones. Por otro lado, una parte del grupo manifestó con un $6 \%$ que las campañas de promoción intercultural servirían entre los dos países servirían para que la recepción de la cultura japonesa tenga mayor aceptación.

Variable: Imaginario social.

Dimensión: Construcción de aficiones.

Indicador: Identificación visual.

Técnica: Escala de combinación.

5. Las expresiones fanáticas que se construyen por medio de la identificación visual a través del anime y la cultura japonesa para usted son: 


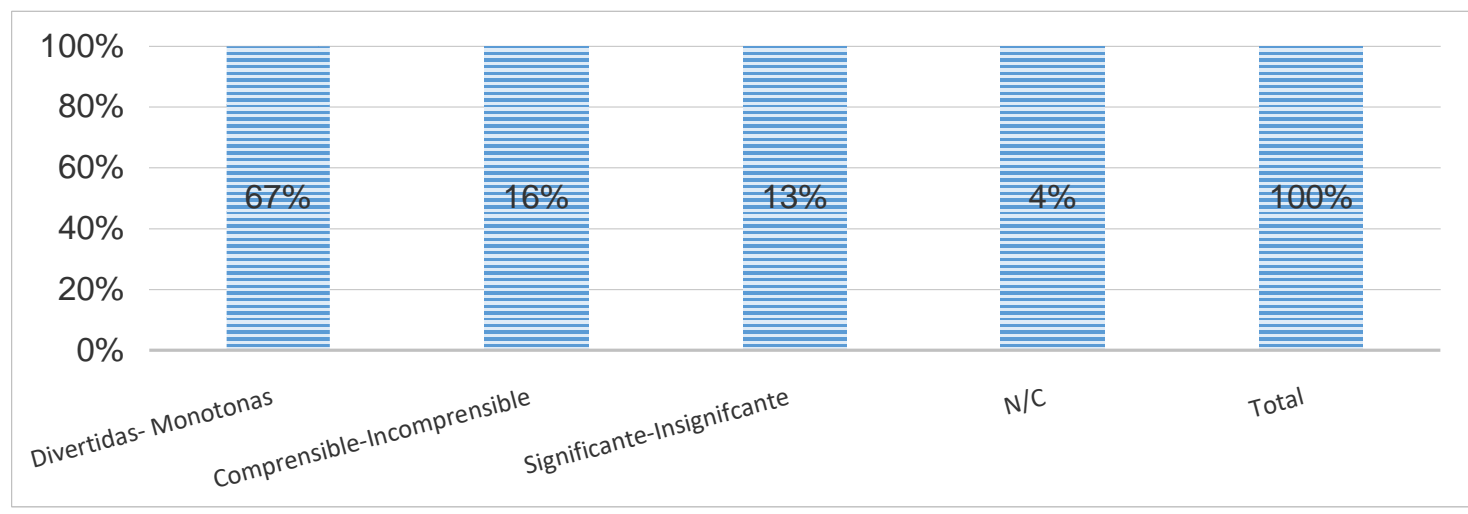

Gráfico 5: identificación visual. Dialmar Intriago (2017).

El público muestral en esta técnica de investigación sostuvo con un $67 \%$ que son DivertidasMonótonas las expresiones fanáticas que se construyen por medio del consumo del anime y cultura japonesa, mostrando que en los interesados existe una identificación visual junto a una aceptación de este contenido y sus representaciones sociales. También un $16 \%$ dijo que le parece Comprensible-Incomprensible y más abajo con un $13 \%$ la respuesta de SignificanteInsignificante. Estas contradicciones medidas en los abordados permiten entender que los imaginarios sociales son un fenómeno cambiante que se configuran por medio de los elementos que le genera el contexto y la percepción que se tiene del mismo.

Variable: Imaginario social.

Dimensión: Interculturalidad-Transculturización.

Indicador: Nuevas representaciones sociales.

Técnica: Inserción de texto.

En esta técnica se le presenta al público muestral una cita (vinculada al Indicador) para que pueda responder sobre la dimensión establecida.

En el texto, Héroes mediáticos y representaciones sociales de justicia y del ideal de moral en la formación ciudadana de los jóvenes, expone: "Pensar que las representaciones sociales trazan mapas de significados que orientan el comportamiento y los diversos intercambios comunicativos. De este modo, no podemos desligar las representaciones de la acción, ni reducirlas a contenidos exentos de afectividad" (Herrera, 2016: 79).

6. A partir de la siguiente cita, ¿Qué nuevas formas de representaciones sociales se han originado dentro de su contexto a partir de la recepción del anime y contenido japonés? 


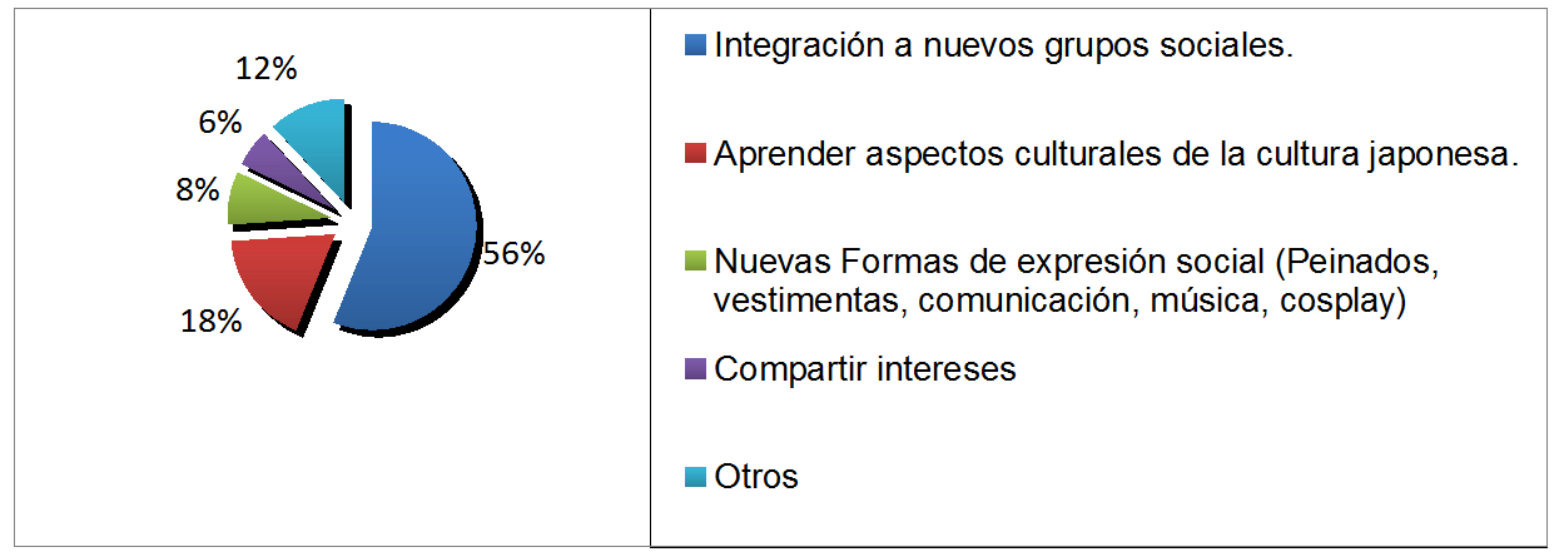

Gráfico 6: representaciones sociales. Dialmar Intriago (2017).

El público contestó con un $56 \%$ que la integración a nuevos grupos sociales dentro de su contexto, esto permite entender que la animación nipona no es solo utilizada como una vía para conocer aspectos culturales, sino que también se lo definiría como un agente socializador. Otra respuesta que coincidió entre los abordados, con un $18 \%$, es que el aprendizaje de nuevas expresiones culturales de un país, es importante como representación social esquematiza una influyente interactividad con la industria cultural japonesa.

Variable: Imaginario social.

Dimensión: Interculturalidad-Transculturización.

Indicador: Respuesta sociocultural.

Técnica: Test proyectivo.

7. Por medio de la observación de la siguiente imagen, ¿Qué significa para usted la cultura japonesa? 


\section{@) $\odot \Theta \Theta$}

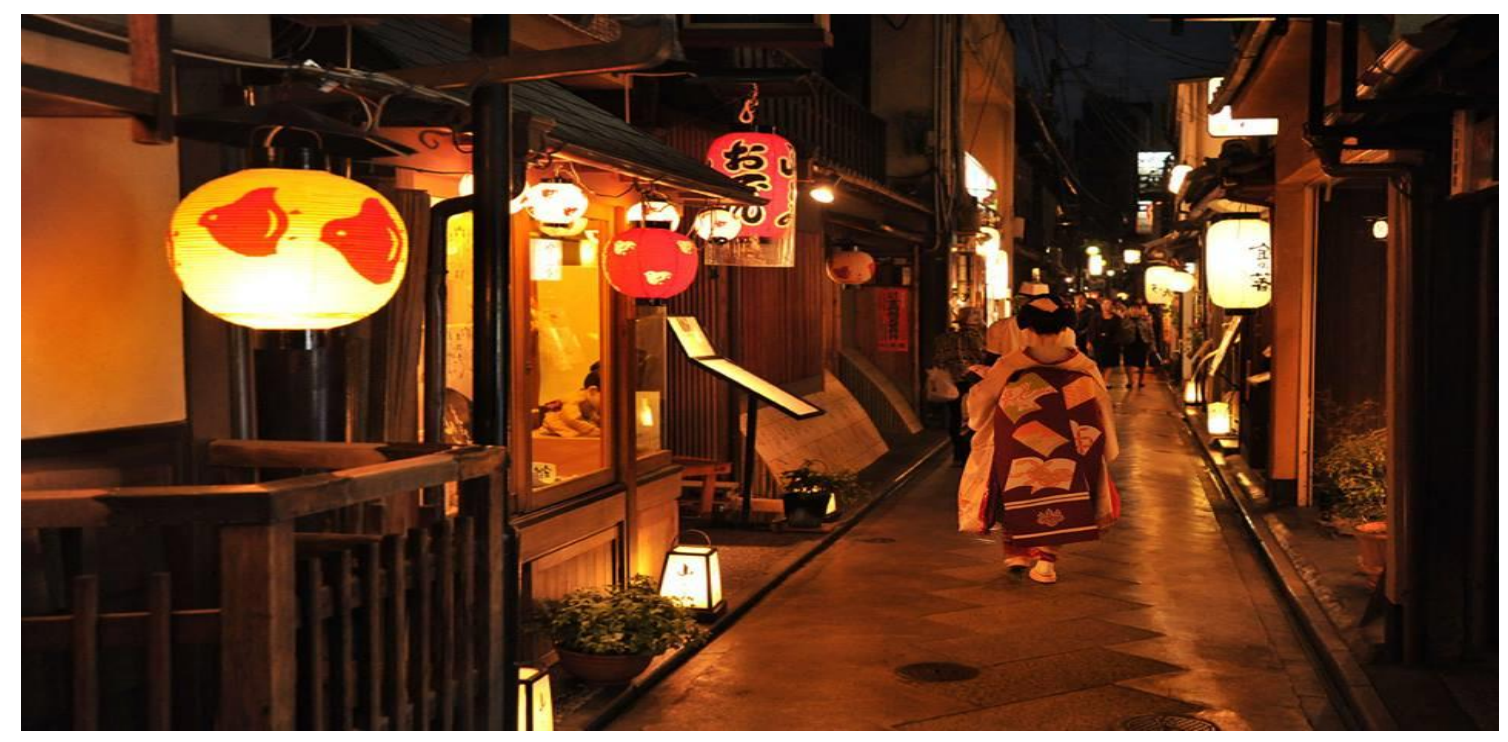

Figura 4: Japon and more Facebook. Rafael Becks (2016).

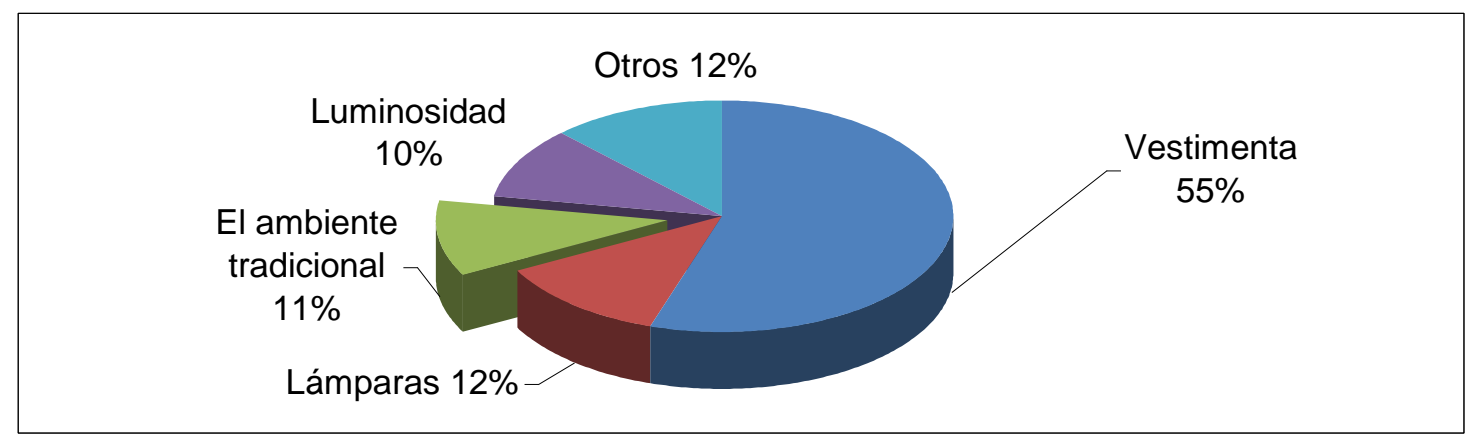

Gráfico 7: respuesta sociocultural. Dialmar Intriago (2017).

En este test proyectivo se afirmó con un 55\% la vestimenta tradicional de la cultura japonesa, mostrando como un elemento representativo e importante por su grado de identificación. Los abordados, aunque destacaban el atuendo no reconocen el nombre, esto como punto débil en la carencia de información de esta vestimenta. Seguido a este porcentaje con un $12 \%$ otro elemento que se recalcó, fue las lámparas características de la cultura no solo japonesa sino oriental como una representatividad. Seguido a estas interpretaciones, con un $11 \%$ está la luminosidad de estas lámparas, resaltadas como una figura que llama la atención de esta cultura en conjunto al ambiente tradicional de las ciudades y propuesto por un $10 \%$ de los consultados. 


\section{Discusión}

El anime es considerado un instrumento influyente y efectivo que ha generado la industria cultural japonesa dentro de las audiencias, concibiendo en la actualidad resultados positivos para el posicionamiento de contenidos masivos que exponen diferentes representaciones culturales de la sociedad nipona.

En el presente estudio, la recepción comunicológica, con un $82 \%$, que tiene el público abordado con el anime, se dan por medios de las redes sociales y páginas especializadas, esto muestra con un $93 \%$ una aceptación de los elementos culturales interiorizados en las narrativas de la animación japonesa, seguido de esta aprobación con $60 \%$, surge un interés por la parte argumentativa y gráfica que permiten que el proceso del consumo del anime e interacción cultural tenga mayor efectividad.

Entre los abordados afirmaron con un $61 \%$ que es importante que dentro de esta recepción comunicológica se promuevan campañas o conferencias que contengan estrategias comunicativas, a cargo de la embajada de Japón en Ecuador, que sirvan para generar espacios donde elementos y aspectos interculturales fortalezcan las relaciones bilaterales entre los dos países.

Las nuevas representaciones culturales son parte del marco de imaginarios sociales, donde los abordados manifestaron las diferentes formas de interacción social. Las más significativas es la integración a nuevos espacios sociales con un 55\%. Otras respuestas destacadas son el conocimiento de la cultura japonesa y la comprensión de nuevas expresiones culturales de su interés, estas se conciben dentro del contexto de los fanáticos a partir de la visualización del anime.

Por medio de este análisis se expone una interculturalidad activa en los estudiantes de Diseño gráfico por la cultura japonesa. Consultando sus respuestas socioculturales, un 55\% reconocen diversos elementos culturales (vestimenta, tradiciones, festivales, idioma, otros), generadas por un sentido de representación, las cuales promueven la construcción del imaginario. Estas respuestas a esas aficiones son previamente estructuradas por un proceso de representación mental abstraído por la disposición que tienen con los contenidos de animación provenientes de Japón. 


\section{Conclusiones}

Este trabajo expone teorías sobre cultura, recepción, anime e interacción social, como los abordajes más destacados, siendo las bases elementales para entender los fenómenos sociales que se abarcan en este estudio. La metodología utilizada fue el interaccionismo simbólico, pues dentro de esta escuela filosófica se analizan las significaciones interpretativas que tiene el sujeto con el objeto por medio de la interacción social dentro de su contexto.

El diseño de investigación es no experimental- transaccional de tipo descriptivo, donde las variables que se expondrán en este estudio serán descritas y no se van a modificar. Las variables elegidas para esta investigación son la recepción comunicológica y el imaginario social, las cuales permiten diagnosticar la interacción que tienen los estudiantes de Diseño gráfico con los contenidos japoneses, con sus diferentes elementos culturales, y los procesos sociales que generan.

La variable imaginario social determina que la construcción de aficiones se genera examinando la identificación visual y las formas de expresión por medio del cuerpo que tienen los fanáticos. (cosplay, grupos sociales, expresiones culturales, intereses y formas de vida). Asimismo, dentro de la determinación de esta influencia cultural en los estudiantes se analizan procesos como la interculturalidad y transculturización, dando como resultado principal un intercambio de cultura sin dejar sus bases socioculturales.

En base a este estudio se busca fortalecer los lazos bilaterales entre Ecuador y Japón, socializando la interculturalidad que tienen las audiencias guayaquileñas que consumen el anime y contenido proveniente del país nipón. Por lo expuesto con anterioridad, la hipótesis comprueba que el proceso influyente que tiene el anime japonés es por medio de su recepción comunicológica, reforzando en sus representaciones parte de un imaginario social.

\section{Recomendaciones}

En el desarrollo de las investigaciones enfocadas en la comunicación de tipo cultural sobre el anime es importante consultar el trabajo de los teóricos Edgar Morín, Manuel Martin Barbero y Manuel Martin Serrano.

Para la elección de un tema de investigación viable determinando una unidad de observación accesible y relacionada a la realización de la temática en la parte del desarrollo de 
antecedentes, marco teórico y otros, se utilizan artículos científicos o trabajos de titulación certificados en el repositorio de sus universidades.

La metodológica sugerida en este tipo de trabajos es el interaccionismo simbólico porque permite establecer la relación sujeto-objeto a partir de la interacción que tiene el sujeto con su contexto y las significaciones que genera a partir de las mismas. Dentro del proceso de abordaje a la unidad de observación certificar con el número de participantes establecidos, para que el desarrollo del trabajo de campo este acorde a los protocolos científicos.

\section{Bibliografía}

Becks, R. (2016). Una Geisha me contó su historia. Página de Facebook Japón and more. Recuperado de https://bit.ly/2Js8Bdr.

Bordei, A. (2010). IKEA-Una compañía multinacional en la época de la globalización. La influencia de la cultura en la comunicación publicitaria. (Tesis de Maestría). Departamento de Comunicación, Universidad Pompeu Fabra. Barcelona, España.

Carazo, L. (2015). Psycho Pass: entre la ética y la filosofía. Revista Espirales, 3(3). Recuperado de http://ojs.udc.edu.co/index.php/espirales/article/view/664/569.

Dávila, A. (2016). Recepción televisiva y mediación representada en la serie los Simpson. (Ensayo para obtener el título de Licenciado en Comunicación). Facultad de Ciencias Políticas y Sociales, Universidad Autónoma del Estado de México.

González, M. (2016). Espacio público de mujeres en Egipto. Un recorrido por la imagen y el imaginario social de las bailarinas. (Tesis Doctoral). Departamento de Estudios Semíticos. Áreas de Estudios Árabes e Islámicos de la Universidad de Granada, España.

Habermas, J. (2011). Teoría de la Acción Comunicativa. Madrid, España: Grupo Editorial Catedra.

Herrera, F. (2012). Análisis simbólico de la serie de animación japonesa "Dragon Ball" para entender el control de la cultura oriental en el mundo. (Tesis de licenciatura). Facultad de Comunicación Social, Universidad Central del Ecuador.

Martín, M. (2014). Cuando la ciencia de la comunicación está implicada en la existencia del presente y la construcción del futuro. Revista científica Contratexto, 22, pp. 37-49. Recuperado de https://revistas.ulima.edu.pe/index.php/contratexto/article/view/87/80. 
Martin-Barbero, J. (2010). De los Medios a las Mediaciones: Comunicación, Cultura y Hegemonía. Barcelona, España: Editorial Anthropos.

Martínez, I. (2014). La publicidad en Japón: El manga y anime como herramientas publicitarias.

(Trabajo de Grado en Publicidad y Relaciones Públicas). Universitat Jaume I, España.

Jenkins, H. (2006). Convergence Culture. Barcelona-España: Editorial Paidós Ibérica SA.

Martínez, J. (2015). La filosofía del viento: un análisis del lenguaje en el cine de Hayao Miyazaki. Revista Hoja Lata Recuperado de http://revistasum.umanizales.edu.co/ojs/index.php/hojalata/article/viewFile/779/859

Morales, P. (2015). Estudio de los imaginarios que se construyen a través del manga y anime en las culturas otaku y cosplay. (Tesis de licenciatura). Facultad de Comunicación Social, Universidad Central del Ecuador.

Morín, E. (2000). Antropología de la Libertad. Gazeta de Antropología. Recuperado de http://www.ugr.es/ pwlac/G16_01Edgar_Morin.pdf.

Porto, L. (2014). Proceso de socialización y cine de animación de Disney y Pixar: estudio del tratamiento de conflictos emocionales en la audiencia de 5 a 11 años. (Tesis Doctoral). Facultad de Ciencias de la Información, Universidad Complutense de Madrid, España.

Rodríguez, R. (2014). El cine de animación japonés: un estudio analítico de la obra de Satoshi Kon. (Tesis Doctoral). Facultad de Ciencias de la Información, Universidad Complutense de Madrid, España.

Torti, Y. (2016). Los nuevos productos culturales digitales en Argentina. Fanfics, fanart y fan videos en la cultura del fandom de Buenos Aires (2001-2012). (Tesis de Maestría en Industria Culturales). Universidad Nacional de Quilmes, Argentina. 